PAPER

\title{
Mucuna pruriens in Parkinson's disease: a double blind clinical and pharmacological study
}

\author{
R Katzenschlager, A Evans, A Manson, P N Patsalos, N Ratnaraj, H Watt, L Timmermann, \\ R Van der Giessen, A J Lees
}

J Neurol Neurosurg Psychiatry 2004;75:1672-1677. doi: 10.1136/jnnp.2003.028761

See end of article for authors' affiliations

....................

Correspondence to: Professor A J Lees, Reto Lila Weston Institute of Neurological Studies, Windeyer Building, 46 Cleveland Street, London, WIT 4JF, UK alees@ion.udl.ac.uk

Received 19 September 2003 In revised form 23 January 2004 Accepted

19 February 2004 Background: The seed powder of the leguminous plant, Mucuna pruriens has long been used in traditional
Ayurvedic Indian medicine for diseases including parkinsonism. We have assessed the clinical effects and levodopa (L-dopa) pharmacokinetics following two different doses of mucuna preparation and compared them with standard L-dopa/carbidopa (LD/CD).

Methods: Eight Parkinson's disease patients with a short duration L-dopa response and on period dyskinesias completed a randomised, controlled, double blind crossover trial. Patients were challenged with single doses of $200 / 50 \mathrm{mg} L D / C D$, and 15 and $30 \mathrm{~g}$ of mucuna preparation in randomised order at weekly intervals. L-Dopa pharmacokinetics were determined, and Unified Parkinson's Disease Rating Scale and tapping speed were obtained at baseline and repeatedly during the $4 \mathrm{~h}$ following drug ingestion. Dyskinesias were assessed using modified AIMS and Goetz scales.

Results: Compared with standard LD/CD, the $30 \mathrm{~g}$ mucuna preparation led to a considerably faster onset of effect (34.6 $v 68.5 \mathrm{~min} ; p=0.021)$, reflected in shorter latencies to peak L-dopa plasma concentrations. Mean on time was $21.9 \%$ (37 $\mathrm{min}$ ) longer with $30 \mathrm{~g}$ mucuna than with LD/CD ( $\mathrm{p}=0.021$ ); peak L-dopa plasma concentrations were $110 \%$ higher and the area under the plasma concentration $v$ time curve (area under curve) was $165.3 \%$ larger $(p=0.012)$. No significant differences in dyskinesias or tolerability occurred.

Conclusions: The rapid onset of action and longer on time without concomitant increase in dyskinesias on mucuna seed powder formulation suggest that this natural source of L-dopa might possess advantages over conventional L-dopa preparations in the long term management of PD. Assessment of long term efficacy and tolerability in a randomised, controlled study is warranted.
M ucuna pruriens (also known as "the cowhage" or "velvet" bean; and "atmagupta" in India) is a climbing legume endemic in India and in other parts of the tropics including Central and South America. Sanskrit incunabula suggest it has been used by the ancients since 1500 BC for the treatment of medical ailments. Ayurvedic texts describe Kampavata, a nervous malady bearing similarities to Parkinson's syndrome, responding to atmagupta (mucuna), ${ }^{1}$ and mucuna seed preparations are in contemporary use for the treatment of Parkinson's disease (PD) in India. ${ }^{2}$ Levodopa (L-dopa) was first isolated from the seeds of $M$ pruriens in $1937^{3}$ and when the value of L-dopa for the treatment of PD became known, scientific interest in plants rich in L-dopa was revived. Three open label studies, ${ }^{4-6}$ which involved between 18 and 60 patients and used mean dosages of $45 \mathrm{~g} /$ day of mucuna seed powder extract (contains about $1500 \mathrm{mg}$ L-dopa), reported significant improvements in parkinsonism for 12-20 weeks. One study ${ }^{5}$ suggested tolerability might be better with mucuna than with standard L-dopa preparations.

No published randomised, controlled studies have as yet provided evidence of the efficacy of mucuna extracts in the treatment of PD. The aim of our study was to determine in a double blind fashion whether a particular mucuna seed powder formulation was comparable or superior to synthetically manufactured L-dopa with respect to anti-parkinsonian effect, tolerability, and L-dopa pharmacokinetic profile.

\section{METHODS}

\section{Patient selection}

Patients with idiopathic PD fulfilling the Queen Square Brain Bank criteria ${ }^{7}$ with motor fluctuations and disabling peak dose dyskinesias after each morning L-dopa dose and with a well defined short duration (1.5-4 h) L-dopa response were eligible for inclusion. They were also required to have been stable on fixed doses of anti-parkinsonian treatment for a period of at least 1 month prior to starting the study.

Patients were excluded if their current drug regime included slow-release formulations of L-dopa, catechol $O$-methyltransferase (COMT) inhibitors, selegiline, anticholinergic drugs, or other drugs that could potentially interfere with gastric absorption (for example, antacids and anti-emetics). Patients showing signs of active psychosis or those on antipsychotic treatment, or patients with clinically relevant cognitive impairment, defined as a Mini Mental State Examination ${ }^{8}$ score of less than 24, were also ineligible. Other exclusion criteria were risk of pregnancy; Hoehn and Yahr stage 5 when "off"; severe, unstable diabetes mellitus; or medical conditions such as unstable cardiovascular disease or moderate to severe renal or hepatic impairment.

\section{Study design and study drug}

The trial was randomised, double blind, and crossover in design. The main outcome measures were differences in the duration of on periods and in dyskinesia scores during single dose L-dopa challenges. Each patient received a single dose challenge with L-dopa/carbidopa (LD/CD), and the 15 and $30 \mathrm{~g}$ mucuna powder preparations in a pre-determined, randomised order generated by computer and based on the

Abbreviations: AIMS, Abnormal Involuntary Movements Scale; AUC, area under curve; $C D$, carbidopa; $C O M T$, catechol O-methyltransferase; LD, levodopa; 3-OMD, 3-O-methyl-dopa; UPDRS, Unified Parkinson's Disease Rating Scale 
order of entry into the study. The study drugs were kept at the pharmacy of the National Hospital for Neurology and Neurosurgery and dispensed by an independent pharmacist.

The two doses of the mucuna preparation were chosen to correspond to either $100 \mathrm{mg}$ (one sachet containing $7.5 \mathrm{~g}$, that is $500 \mathrm{mg}$ of neat L-dopa) or $200 \mathrm{mg}$ (two sachets together containing $1000 \mathrm{mg}$ of neat L-dopa) of L-dopa in the presence of a decarboxylase inhibitor. This conversion factor was based on published studies comparing clinical and pharmacokinetic L-dopa effects with and without a decarboxylase inhibitor. ${ }^{9-13}$

The mucuna seed powder preparation was a light, yellowish powder, manufactured in Germany (Wiewelhove, Ibbenbueren, Germany) from raw material obtained in India. To enhance stability, dissolving properties, and taste, the following additives per unit (per sachet) were added: ascorbic acid $(0.188 \mathrm{~g})$, tangerine oil $(0.09 \mathrm{~g})$, silicium dioxide $(0.262 \mathrm{~g})$, saccharine- $\mathrm{Na}$ and citric acid (0.075 g), sorbitol $(1.207 \mathrm{~g})$, and lecithin $(0.34 \mathrm{~g})$. Matching placebo sachets contained powder of identical consistency, colour, and taste. Quality assurance certificates for the preparation and for placebo were obtained from an independent laboratory (LAT, Munich, Germany). Chromatographic analysis demonstrated an L-dopa content of $4.86 \%$ or $250 \mathrm{mg}$ per sachet. The Medicines Control Agency, Department of Health, UK, issued an exemption from licences order for the study drug. The study was approved by the Joint Ethics Committee of University College London/University College London Hospitals. All patients gave informed consent.

\section{Single dose challenges}

Patients were admitted to hospital for an overnight stay on three occasions each separated by 1 week. Challenges were performed at exactly the same time in the morning in each patient, after withdrawal of all anti-parkinsonian medication from midnight, and patients took nothing by mouth with the exception of black tea or coffee and water. Patients were randomised to the order of the days on which they would receive the three trial medications:

- $200 \mathrm{mg}$ L-dopa/50 mg decarboxylase inhibitor (carbidopa) as capsule formulation plus four sachets of placebo as a powder formulation closely resembling mucuna seed powder in consistency and flavour, dissolved in a glass of water, or:

- $15 \mathrm{~g}$, that is, two sachets of mucuna seed powder (containing $500 \mathrm{mg}$ of L-dopa) plus two sachets of placebo powder plus a placebo capsule identical in shape, colour, and taste to the $\mathrm{LD} / \mathrm{CD}$ capsule, or:

- $30 \mathrm{~g}$, that is, four sachets of mucuna seed powder (containing $1000 \mathrm{mg}$ of L-dopa) plus a placebo capsule.

\section{L-Dopa and 3-O-methyl-dopa (3-OMD) analysis}

Blood samples were taken at baseline and 15, 30, 45, 60, 75, $90,105,120,140,160,180,210$, and $240 \mathrm{~min}$ after intake or until a full off-state had been reached if this occurred earlier than 240 min after drug ingestion. Samples were dispensed into EDTA tubes and centrifuged immediately at the end of each assessment. Plasma was stored at $-70^{\circ} \mathrm{C}$ until analysed. L-Dopa and 3-OMD concentrations were determined by high performance liquid chromatography, using an automated Gilson system (Anachem, Luton, Bedfordshire, UK) and an ESA Coulochem II electrochemical detector with a guard cell and an analytical cell. Chromatographic separation was achieved using a Hypersil BDS-C18 column (Hewlett Packard, Stockport, Cheshire, UK). A $50 \mu \mathrm{l}$ plasma sample and $150 \mu \mathrm{l}$ sodium chloride solution $(0.9 \%)$ were vortex mixed. Then $10 \mu \mathrm{l} 60 \%$ perchloric acid was added and after further vortex mixing and centrifugation, $100 \mu \mathrm{l}$ of the aqueous layer was transferred into an autosampler vial, from which $10 \mu \mathrm{l}$ was injected into the column. Within batch precision and between batch precision for L-dopa $(150 \mathrm{ng} / \mathrm{ml})$ and 3 -OMD ( $375 \mathrm{ng} / \mathrm{ml}$ ) were $<2.0 \%$ and $<7.0 \%$, respectively (coefficient of variation, CV). The lower limit of quantitation was $10 \mathrm{ng} / \mathrm{ml}$ for L-dopa and $100 \mathrm{ng} / \mathrm{ml}$ for 3 $\mathrm{OMD}(\mathrm{CV}<8 \%)$ and the lower limit of detection was $1 \mathrm{ng} / \mathrm{ml}$.

\section{Pharmacokinetic parameters}

L-Dopa concentration $v$ time profiles were analysed according to a one-compartment model. The parameters computed were: area under the concentration $v$ time curve (AUC) and apparent elimination half life $\left(t_{1 / 2}\right)$. The AUC from time 0 to $260 \mathrm{~min}$ was calculated by the trapezoid rule. Time to maximum concentration $\left(\mathrm{T}_{\max }\right)$ and maximum concentration $\left(\mathrm{C}_{\max }\right)$ were obtained by visual inspection of the L-dopa concentration $v$ time profiles.

\section{Clinical assessments}

Motor function was assessed at baseline and then immediately following each blood sample. Motor function was assessed using the UPDRS (Unified Parkinson's Disease Rating Scale) motor score. Hand function on the patient's more affected side was assessed with the "Brain Test", ${ }^{14}$ using the keyboard of a laptop computer.

\section{Dyskinesia assessments}

Once patients had reached their full on state, video recordings were performed on three occasions at $20 \mathrm{~min}$ intervals. As certain mental and motor tasks have been shown to increase dyskinesias, ${ }^{15}$ the following "activation" tasks were carried out in an identical fashion at each visit:

1. Sitting still for $1 \mathrm{~min}$

2. Performing mental calculations

3. Putting on and buttoning a coat

4. Picking up and drinking from a cup of water

5. Walking

Videotapes were rated independently by two blinded raters (RK and AE), using modified versions of the Goetz rating scale $^{16}$ and the Abnormal Involuntary Movements Scale (AIMS). ${ }^{17}$ Both are five point (0-4) scales: AIMS rates visible dyskinesias in various body parts, and Goetz rates overall impairment caused by dyskinesias during motor tasks. Tasks 1 and 2 were rated using AIMS, but facial muscles and global rating were excluded. Therefore the maximum score was 24 for each task (that is, summed ratings for neck, trunk, and each limb). Tasks 3-5 were assessed on the Goetz scale, modified by excluding phenomenological rating and by counting only choreatic movements.

Full blood count, and liver and renal function blood tests were taken at baseline and after completion of the study.

\section{Blinding}

Randomisation information was kept in a blinded format with the company that had manufactured and supplied the active drugs and matching placebos. Emergency envelopes with the randomisation code were also kept with the head pharmacist at the National Hospital for Neurology and Neurosurgery. Blinding was maintained until after the database was locked.

\section{Sample size calculation}

The trial was powered to detect a $25 \%$ difference between AIMS scores on the interventions, considered a clinically relevant change based on previous publications ${ }^{18}$ and clinical judgment. Power calculation showed that eight patients 
Table 1 Measures of parkinsonism on LD/CD, and 15 and $30 \mathrm{~g}$ of mucuna

\begin{tabular}{|c|c|c|c|c|c|}
\hline & $\mathrm{LD} / \mathrm{CD}$ (SD) & $15 \mathrm{~g}$ mucuna (SD) & $30 \mathrm{~g}$ mucuna (SD) & $\begin{array}{l}\text { Difference LD/CD } \\
v 15 \mathrm{~g} \text { mucuna } \\
\text { ( } \mathrm{p} \text { value) }\end{array}$ & $\begin{array}{l}\text { Difference LD/CD } \\
\text { v } 30 \mathrm{~g} \text { mucuna } \\
\text { (p value) }\end{array}$ \\
\hline UPDRS baseline & $49.8(12.7)$ & $49.5(15.3)$ & $46.9(10.7)$ & NS & 0.046 \\
\hline Tapping baseline & $47.4(11.0)$ & $44.0(12.6)$ & $45.0(13.6)$ & NS & NS \\
\hline Best UPDRS "on" & $15.4(7.8)$ & $15.5(7.6)$ & $15.5(8.5)$ & NS & NS \\
\hline Best tapping "on" & $75.5(21.3)$ & $78.5(21.3)$ & $79.1(15.0)$ & NS & NS \\
\hline Duration of full "on" & $167.4(55.3)$ & $147.3(30.5)$ & $204.0(55.1)$ & NS & 0.021 \\
\hline Duration of full plus partial "on" & $232.0(84.8)$ & $170.3(38.0)$ & $278.1(53.9)$ & 0.036 & 0.036 \\
\hline Time to full "on" & $68.5(29.0)$ & $45.6(30.4)$ & $34.6(13.6)$ & 0.035 & 0.021 \\
\hline Time to beginning of "on" & $54.6(24.5)$ & $27.8(14.1)$ & $23.0(11.5)$ & 0.012 & 0.012 \\
\hline
\end{tabular}

LD/CD, L-dopa/carbidopa; SD, standard deviation.

All times indicated in minutes. Tapping: see Methods. UPDRS refers to motor score. Partial "on": any clinical state where parkinsonism was above baseline level before and after reaching a full "on" state.

completing both treatment arms were required for $80 \%$ power at the $5 \%$ significance level.

\section{Data analysis}

The two video raters' dyskinesia scores were combined for analysis. Interrater reliability was assessed using kappa analysis, weighted according to how close agreement between the raters was (Stata Statistical Software Release 6.0 ). The average of the two raters was used in the statistical analysis. Due to sample sizes, all data sets were assessed for normality by inspection of histograms. Means were compared using Wilcoxon's non-parametric signed ranks test or pairedsamples $t$ test, as appropriate.

\section{RESULTS}

Nine patients (five women and four men) were enrolled in the study. One patient dropped out due to shortlasting vomiting following ingestion of the first study medication (30 g mucuna), which was considered to have reduced the amount available for absorption. Eight patients completed the study. Patients' mean age was 62.2 years (range 50-72); mean disease duration was 12.4 years (range 7-17); and mean Hoehn and Yahr stage (when "off") was 3.5 (range 2.5-4). Patients took a mean daily L-dopa dose of $572 \mathrm{mg}$ (range 200-1000 mg) prior to the trial. Other antiparkinsonian medications taken were amantadine in two $(200 \mathrm{mg})$, pergolide in three (mean, $3.2 \mathrm{mg}$ ), and ropinirole (18 mg), cabergoline $(6 \mathrm{mg})$, and pramipexole $(1.4 \mathrm{mg})$ in one patient each.

\section{Clinical assessments}

Results and statistical significance of differences are shown in tables 1 and 2. Duration of full on-time was $21.9 \%$ longer with the $30 \mathrm{~g}$ mucuna dose compared with LD/CD. Time from beginning of switching on to returning to a full off state was increased by $19.8 \%$ with 30 g mucuna but was $26.6 \%$ shorter with $15 \mathrm{~g}$ mucuna. The mucuna preparations reduced the latency from drug ingestion to achieving a full on-state: this was $33.4 \%$ or 23 min shorter with $15 \mathrm{~g}$ mucuna than with $\mathrm{LD} / \mathrm{CD}$, and $49 \%$ or $34 \mathrm{~min}$ shorter with $30 \mathrm{~g}$ mucuna. Similarly, time to beginning of switching on was reduced by $49 \%$ or 27 min with $15 \mathrm{~g}$ mucuna and by $57.9 \%$ or $31.6 \mathrm{~min}$ with $30 \mathrm{~g}$ mucuna. Best UPDRS motor scores and tapping speed when "on" did not differ significantly among the three study drugs.

\section{Dyskinesia rating of video recordings}

Interrater reliability was good: weighted kappa was 0.45 $(\mathrm{p}<0.0001)$ for Goetz scores (Spearman's rank 0.87, $\mathrm{p}<0.0001)$ and $0.62 \quad(\mathrm{p}<0.0001)$ for AIMS scores (Spearman's rank 0.97, $\mathrm{p}<0.0001$ ). No significant differences in dyskinesia ratings were found among the study drugs.

\section{L-Dopa (and 3-OMD) pharmacokinetics}

The plasma concentration $v$ time profiles of L-dopa after LD/ CD, 15 and $30 \mathrm{~g}$ mucuna ingestion are shown in fig $1 \mathrm{~A}$. Fig $1 \mathrm{~B}$ shows the concurrent profiles for 3-OMD. The pharmacokinetic constants, as calculated from the logarithmic concentration $v$ time plots of individual patients, are shown in table 3 . The mean L-dopa value was $165 \%$ larger after $30 \mathrm{~g}$ mucuna compared with $\mathrm{LD} / \mathrm{CD}$ and this difference was significant. Mean L-dopa $\mathrm{C}_{\max }$ was $110 \%$ higher after $30 \mathrm{~g}$ mucuna compared with LD/CD and 19\% higher after $15 \mathrm{~g}$ mucuna. Mean $\mathrm{T}_{\max }$ values were $35 \%$ and $24 \%$ shorter after 15 and $30 \mathrm{~g}$ mucuna, respectively, compared with LD/CD. There were no significant differences in $t_{1 / 2}$ when the three study drugs were compared. In contrast to L-dopa AUC values, 3-OMD AUC values were not significantly different between the three study regimens although values tended to be higher in patients administered LD/CD.

\section{Safety and tolerability}

Apart from one patient who dropped out due to shortlasting vomiting on $30 \mathrm{~g}$ mucuna, the other adverse events were: mild and shortlasting nausea occurring in two patients with $\mathrm{LD} / \mathrm{CD}$ and in two patients with $30 \mathrm{~g}$ mucuna; mild gastric pain in one patient with $\mathrm{LD} / \mathrm{C}$; and mild dizziness in one patient each with LD/CD and $15 \mathrm{~g}$ mucuna. No clinically relevant changes in haematology or biochemistry parameters were observed.

\section{DISCUSSION}

Our study demonstrates that the seed powder formulation of $M$ pruriens contains a considerable quantity of L-dopa which, at a dose of $30 \mathrm{~g}$, is sufficient to consistently induce a sustained on-period in fluctuating PD patients with short

Table 2 Dyskinesia measures on LD/CD, and 15 and $30 \mathrm{~g}$ mucuna

\begin{tabular}{|c|c|c|c|c|c|}
\hline & $\mathrm{LD} / \mathrm{CD}$ (SD) & $15 \mathrm{~g}$ mucuna (SD) & $30 \mathrm{~g}$ mucuna (SD) & $\begin{array}{l}\text { Difference } L D / C D \vee 15 \mathrm{~g} \\
\text { mucuna ( } \mathrm{p} \text { value) }\end{array}$ & $\begin{array}{l}\text { Difference } L D / C D \vee 30 \mathrm{~g} \\
\text { mucuna ( } p \text { value) }\end{array}$ \\
\hline Mean AIMS score & $8.0(3.2)$ & $8.6(3.5)$ & $8.0(3.3)$ & 0.12 & 0.79 \\
\hline Mean Goetz score & $2.0(0.5)$ & $2.1(0.5)$ & $1.9(0.4)$ & 0.13 & 0.36 \\
\hline
\end{tabular}


Table 3 Pharmacokinetic parameters for L-dopa and 3-OMD with LD/CD, and 15 and $30 \mathrm{~g}$ mucuna

\begin{tabular}{|c|c|c|c|c|c|}
\hline & LD/CD (SEM) & $15 \mathrm{~g}$ mucuna & $30 \mathrm{~g}$ mucuna & $\begin{array}{l}\text { Difference } L D / C D \\
\text { v } 15 \mathrm{~g} \text { mucuna } \\
\text { (p value) }\end{array}$ & $\begin{array}{l}\text { Difference LD/CD } \\
\text { v } 30 \mathrm{~g} \text { mucuna } \\
\text { (p value) }\end{array}$ \\
\hline \multicolumn{6}{|l|}{ L-Dopa } \\
\hline AUC (ng h/ml) & $16243(2543)$ & 16306 (4024) & 43087 (9735) & NS & 0.012 \\
\hline$C_{\max }(\mathrm{ng} / \mathrm{ml})$ & 6956 (1098) & 8608 (1979) & $14606(2662)$ & NS & 0.025 \\
\hline$T_{\max }(\min )$ & 95.5 (10.5) & $61.8(12.9)$ & $72.4(15.1)$ & 0.04 & NS \\
\hline$t_{1 / 2}(\min )$ & $90.8(23.8)$ & $58.6(5.1)$ & $94.0(25.5)$ & NS & NS \\
\hline \multicolumn{6}{|l|}{ 3-OMD } \\
\hline AUC (ng h/ml) & 24267 (4559) & 20292 (2833) & 22698 (2833) & 0.05 & NS \\
\hline
\end{tabular}

AUC, area under the concentration $v$ time curve; $C_{\text {max }}$, peak plasma concentration; $L D / C D$, L-dopa/carbidopa; $S E M$, standard error of the mean; $T_{\max }$, time to peak plasma concentration; $t_{1 / 2}$, apparent plasma elimination half life; 3-OMD, 3-O-methyl-dopa.

duration L-dopa response. The quality of motor improvement was equivalent to that seen with synthetic $\mathrm{LD} / \mathrm{CD}$, but the onset of action, duration of effect, and pharmacokinetic profiles differed considerably.

The latency to clinical onset was significantly and markedly shorter with mucuna than with synthetic LD/CD. The duration of the on-period was significantly longer with $30 \mathrm{~g}$ mucuna than with LD/CD, with a mean difference of $37 \mathrm{~min}$. The time from the beginning of a visible antiparkinsonian effect to returning to a full "off" was significantly longer with $30 \mathrm{~g}$ mucuna, providing an additional $46 \mathrm{~min}$ when patients were partially "on".

Compared to literature reports on dispersible L-dopa formulations, the latency to the onset of effect following mucuna in our study was within a similar range. However,
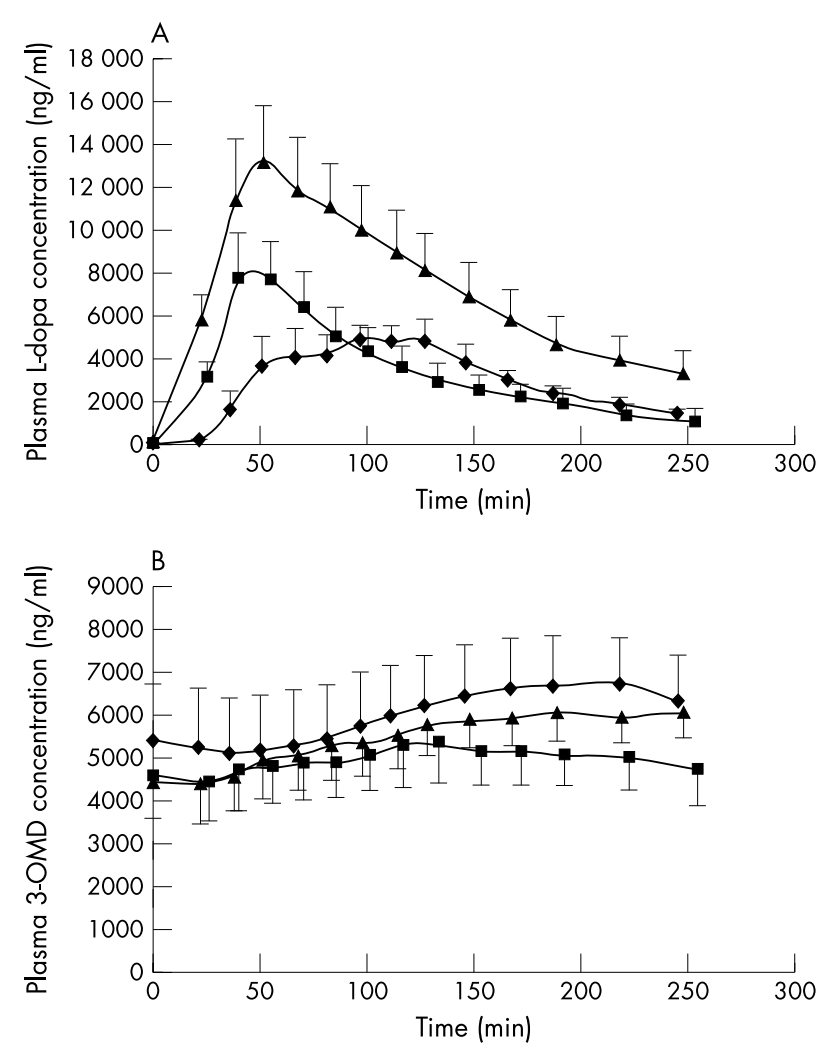

Figure 1 (A) Plasma concentration $v$ time profiles for L-dopa following ingestion of $200 \mathrm{mg} \mathrm{L-dopa} / 50 \mathrm{mg}$ carbidopa (४), $15 \mathrm{~g}$ mucuna ( $\mathbf{\square})$, or $30 \mathrm{~g}$ mucuna ( $\mathbf{\Lambda})$ seed powder. Data are mean (SEM) of eight patients. (B) Plasma concentration $v$ time profiles for 3-OMD following ingestion of $200 \mathrm{mg} \mathrm{L-dopa} / 50 \mathrm{mg}$ carbidopa (•), $15 \mathrm{~g}$ mucuna (口), or $30 \mathrm{~g}$ mucuna ( $\mathbf{\Delta}$ ) seed powder. Data are mean (SEM) of eight patients. the duration of on-time achieved with $30 \mathrm{~g}$ mucuna was considerably longer: the time patients spent in a full on-state was 204 min following $30 \mathrm{~g}$ mucuna, compared with $148^{19}$ and $97 \mathrm{~min}^{20}$ reported in two studies with dispersible L-dopa formulations.

These clinical findings were reflected in the pharmacokinetic profile of L-dopa concentrations, which showed a significantly higher peak plasma concentration with $30 \mathrm{~g}$ mucuna, occurring after a shorter latency $\mathrm{T}_{\max }$. The difference in $\mathrm{T}_{\max }$ was significant with $15 \mathrm{~g}$ and only narrowly missed reaching significance with $30 \mathrm{~g}$.

Peak L-dopa concentrations on mucuna were followed by a decline which was faster with 15 g mucuna but similar to LD/ CD with $30 \mathrm{~g}$ mucuna, resulting in a significantly larger total AUC with 30 g mucuna.

These findings suggest that $M$ pruriens formulations may actually have a higher bioavailability than standard L-dopa preparations. Although the latency to peak concentrations with LD/CD was rather long at $95.5 \mathrm{~min}$, this is within the upper range of reported findings with standard L-dopa preparations. ${ }^{21}{ }^{22}$ All reasonable and practical measures were taken to avoid dietary interferences. Drugs that could inhibit gastrointestinal absorption were excluded, and none of the patients had known malabsorption syndromes or other gastrointestinal conditions. However, all the patients had been on long term L-dopa therapy for many years prior to the study.

The most obvious differences between the mucuna preparation and the synthetic formulation used in this study were the administration of mucuna in the form of a suspension as opposed to a capsule, and the presence of a dopa decarboxylase inhibitor in the standard L-dopa preparation. Decarboxylase inhibitors mainly increase L-dopa plasma concentrations by blocking the peripheral degradation of L-dopa to dopamine, thus allowing more L-dopa to cross the blood-brain barrier. However, the gastrointestinal mucosa is a site for decarboxylation of oral $\mathrm{L}-\mathrm{dopa}^{23}$ and decarboxylase inhibitors have been reported to enhance duodenal L-dopa absorption, ${ }^{24}{ }^{25}$ presumably by inhibiting metabolic pathways such as aromatic dehydroxylation in the gut. ${ }^{22}$ Adding a decarboxylase inhibitor leads to considerably higher peak L-dopa concentrations. ${ }^{9}{ }^{10}{ }^{26}$ One study proposed a doubling of the bioavailability of oral L-dopa in the presence of a decarboxylase inhibitor, but this was based on findings with intravenously administered L-dopa. ${ }^{27}$ Studies investigating oral L-dopa invariably reported a reduction of exogenous Ldopa by $60-80 \% .^{10}{ }^{111328}$ The conversion factor of $1: 5$ chosen for the $30 \mathrm{~g}$ mucuna dose in relation to standard LD/CD (L-dopa reduction by $80 \%$ ) is in the upper range of reported ratios. It is possible that the truly corresponding dose is slightly less than $30 \mathrm{~g}$, but this does not seem sufficient to explain the large differences in pharmacokinetic and clinical findings. 
The impact of decarboxylase inhibitors on latency to peak concentrations varies in the reported literature. This has been found to be either shorter, ${ }^{26}$ similar, ${ }^{10}{ }^{12} 29$ or longer ${ }^{9}$ compared with L-dopa alone, and one study ${ }^{28}$ found a dose-dependent reduction in $\mathrm{T}_{\max }$ in the presence of $\mathrm{CD}$. Although the delay to maximum plasma concentration of $95.5 \mathrm{~min}$ found in our study appears rather long, similar delays on standard release LD/decarboxylase inhibitor have been reported in the literature..$^{28}$ There is no obvious explanation for this finding. All reasonable measures were taken to avoid interference by drugs or food, and none of the patients had evidence of malabsorption syndromes or other gastrointestinal conditions.

In view of previously reported experience with mucuna, our observations of much higher peak L-dopa concentrations and larger AUCs on mucuna are unexpected and surprising. A possible explanation may lie in the administration of mucuna as a suspension: L-dopa is mainly absorbed from the proximal small intestine, and delays in reaching the duodenum through the gastric valve are likely to occur more commonly with any form of coating than with dispersible formulations. This explains why dispersible L-dopa works more quickly than standard preparations. The latency to the onset of a clinical effect with dispersible L-dopa has been reported to be on average $26.8^{20}$ or $27.9 \mathrm{~min}^{19}$ and is thus comparable to the mean latency of 34.6 min observed in our patients with $30 \mathrm{~g}$ mucuna.

Additives contained in the mucuna powder preparation may also have had an impact on absorption: the seed powder preparation used in this study was produced with the aim of achieving as standardised a composition as possible. The small amount of ascorbic acid, added for chemical stability, ${ }^{30}$ may potentially have enhanced intestinal absorption. ${ }^{31}$ Citric acid is also known to have some effect on L-dopa absorption, ${ }^{32}$ but the addition of a small amount of citric acid does not seem likely to be a sufficient explanation for such a marked difference in pharmacokinetics. Some other additives differed slightly from those found in the commonly used commercial Indian preparations, and further investigations into factors that may promote gastrointestinal absorption of the seed powder compound are warranted.

Decarboxylase inhibitors were shown to prolong L-dopa $t_{1 / 2}$ to a moderate degree in most ${ }^{12} 2427$ but not all ${ }^{33}$ studies. In contrast, our own data show a similar rate of decline of L-dopa plasma concentrations with $30 \mathrm{~g}$ mucuna and LD/CD. Although a small residual effect from patients' on going carbidopa medication cannot be excluded due to its plasma $\mathrm{t}_{1 / 2}$ of $3 \mathrm{~h}$, the similarity in the plasma concentration decline between $\mathrm{LD} / \mathrm{CD}$ and $30 \mathrm{~g}$ mucuna raises the possibility of an additional active ingredient in the mucuna preparation with a blocking effect on L-dopa degradation. However, there is as yet no direct evidence of such active agents contained in the plant preparation.

The metabolite 3-OMD showed very similar AUC on mucuna and LD/CD, despite higher peak plasma concentrations of L-dopa with $30 \mathrm{~g}$ mucuna. This can largely be explained by the fact that in the absence of a decarboxylase inhibitor in the mucuna preparation, L-dopa was predominantly metabolised by decarboxylation, leading to smaller concentrations of 3-OMD.

The combination of rapid onset of action with long duration of effect appears to constitute a characteristic of this plant preparation. Previous limited pharmacokinetic reports with mucuna preparations suggested a lower bioavailability of mucuna with a somewhat slower increase and decline of L-dopa plasma concentrations and a lower peak. ${ }^{34}$ However, these comparisons were done with historical controls rather than in a controlled comparison. In contrast, our findings indicate that mucuna formulation may actually have a higher bioavailability than standard LD/CD which may not be explained by dose alone.

It is also noteworthy that despite larger mean L-dopa concentrations associated with $30 \mathrm{~g}$ mucuna, there were no significant differences in dyskinesia severity during the challenges. Although both the longer duration of effect and the larger AUC can in part be explained by higher maximum concentrations reached with $30 \mathrm{~g}$ mucuna, ${ }^{35}$ the differences are striking and raise the possibility of additional explanations.

Another aim of this study was to compare the clinical efficacy and tolerability of the two doses of the mucuna preparation. While a dose of $30 \mathrm{~g}$ of the mucuna preparation led to reliable and sustained antiparkinsonian effects in all patients, this did not always occur with the $15 \mathrm{~g}$ dose, and pharmacokinetic results clearly showed that L-dopa concentrations were considerably lower with the smaller dose.

Tolerability was comparable with all three study drugs. Adverse effects were mild and shortlasting, and the patient who dropped out from the study due to vomiting on $30 \mathrm{~g}$ mucuna fully recovered within a few minutes, and was prepared to stay in the trial. The assessment was discontinued, however, because part of the ingested drug was likely to have become unavailable for absorption.

Acute side effects of L-dopa such as nausea, vomiting, and orthostatic hypotension have been shown to be correlated with plasma concentrations $s^{9}$ and to occur less often in the presence of a decarboxylase inhibitor. ${ }^{96}$ In view of the significantly higher plasma concentrations reached with $30 \mathrm{~g}$ mucuna than $\mathrm{LD} / \mathrm{CD}$, it is encouraging that side effect profiles were similar in our study. However, this lack of difference may have been partly due to the fact that tachyphylaxis and peripheral tolerance to dopamine receptor stimulation occur with chronic L-dopa administration, and different results may have been seen in de novo patients. It might be appropriate to administer mucuna preparation in combination with a peripheral dopa decarboxylase inhibitor which may further improve tolerability and efficacy.

The combination of $M$ pruriens with domperidone, which blocks peripheral dopamine receptors, would also be expected to reduce peripheral adverse events. Domperidone was not used in this study because it has been shown to slightly improve L-dopa absorption. ${ }^{37}$

$M$ pruriens grows widely throughout the tropics and is currently mostly planted to improve soil and provide animal feed, and to a smaller extent, for human consumption. It is believed the biological purpose of the L-dopa concentration is to protect the plant against insect attack. Mucuna contains larger amounts of L-dopa than any other known natural source. $^{38} 39$ Further natural sources of L-dopa include other members of the mucuna genus, such as Stizolobium deeringianum, ${ }^{40}$ and Vicia fava (broad bean), in which L-dopa was identified in 1913. ${ }^{41}$ An open-label study of $250 \mathrm{~g}$ of cooked $V$ fava compared with $100 \mathrm{mg}$ synthetic LD/CD showed lower peak plasma concentrations following the bean meal, and pharmacokinetic profile and clinical effects very similar to synthetic L-dopa. ${ }^{42}$ In an uncontrolled study, ${ }^{38}$ one patient failed to switch on altogether following $150 \mathrm{~g}$ of $V$ fava. Clinical benefit from longer term use has also been reported in an uncontrolled fashion. ${ }^{43}$ Although limited conclusions are possible in the absence of randomised, double blind investigations of $V$ fava, there is no suggestion in the reported literature that it might share the pharmacokinetic properties of mucuna found in our study. Moreover, the use of $V$ fava for the treatment of PD also has practical limitations: the much lower L-dopa content in $V$ fava compared with mucuna requires the ingestion of bulky meals, and there is a risk of favism, a haemolytic anaemia which can occur in persons 
with a genetic deficiency of the enzyme glucose 6-phosphate dehydrogenase.

Recent animal data ${ }^{44}$ have suggested anti-lipid peroxidation effects of an alcohol extract of $M$ pruriens. If confirmed in further studies, this raises the possibility of an additional beneficial role for mucuna.

Based on this preliminary pilot study in patients with PD and short duration L-dopa response, the $30 \mathrm{~g} M$ pruriens formulation seems to possess potential advantages over existing commercially available controlled release or dispersible formulations of L-dopa in that it combines a rapid onset of action with a slightly longer duration of therapeutic response compared with a dose of standard L-dopa calculated on the basis of the known quantity of L-dopa in mucuna using standard conversion ratios. No increase in dyskinesia severity or in peripheral dopaminergic adverse events was found on the mucuna preparation. Further analysis of the seeds' content may reveal further explanations for the differences in the pharmacokinetic profiles found in this study. If these findings can be confirmed in larger and longer term studies, mucuna would seem to be a reasonable commercially viable alternative to standard L-dopa.

\section{ACKNOWLEDGEMENTS}

The authors thank Phytrix, Munich, Germany (formerly CMI-Centers for Medical Innovation AG) for supplying the study drugs.

\section{Authors' affiliations}

R Katzenschlager, A Evans, A J Lees, National Hospital for Neurology and Neurosurgery, London, UK

R Katzenschlager, Department of Neurology, Donauspital/SMZ-Ost, Vienna, Austria

A Manson, Wessex Neurological Centre, University of Southampton, Southampton, UK

P N Patsalos, N Ratnaraj, Department of Clinical and Experimental Epilepsy, Institute of Neurology, London, UK

H Watt, Medical Statistics Unit, London School of Hygiene and Tropical Medicine and Institute of Neurology, Queen Square, London, UK L Timmermann, Department of Neurology, University of Düsseldorf, Düsseldorf, Germany

\section{R Van der Giessen, Phytrix Ltd, Munich, Germany}

Mr Charles Burnett provided an unrestricted grant supporting all expenses for this study

Competing interests: R Van der Giessen is an employee of Phytrix Ltd, Munich

\section{REFERENCES}

1 Manyam B. Paralysis agitans and levodopa in "Ayurveda": ancient Indian medical treatise. Mov Disord 1990:5:47-8.

2 Manyam B, Sanchez-Ramos JR. Traditional and complementary therapies in Parkinsons disease. Adv Neurol 1999;80:565-74.

3 Damodaran M, Ramaswamy R. Isolation of L-dopa from the seeds of Mucuna pruriens. Biochem J 1937;31:2149-451.

4 HP-200 in Parkinson's Disease Study Group. An alternative medicine treatment for Parkinson's disease: results of a multicenter clinical trial. J Altern Complement Med 1995; 1:249-55.

5 Vayda AB, Rajgopalan TS, Mankodi NA, et al. Treatment of Parkinsons disease with the cowhage plant - Mucuna pruriens (Bak). Neurol India 1978;36:171-6

6 Nagashayana N, Sankarankutty P, Nampoothirir MR, et al. Association of L-dopa with recovery following ayurveda medication in Parkinson's disease. J Neurol Sci 2000; 176:124-7.

7 Gibb WRG, Lees AJ. The relevance of the Lewy body to the pathogenesis of idiopathic Parkinson's disease. J Neurol Neurosurg Psychiatry 1988:51:745-52.

8 Folstein MF, Folstein SE, McHugh PR. "Mini-mental state". A practical method for grading the cognitive state of patients for the clinician. J Psychiatr Res 1975; 12:189-98.

9 Rinne UK, Sonninen V, Sirtola T. Plasma concentration of levodopa in patients with Parkinson's disease. Eur Neurol 1973;10:301-10.

10 Mars H. Modification of levodopa effect by systemic decarboxylase inhibition. Arch Neurol 1973;28:91-5.

11 Jaffe M. Clinical studies of carbidopa and L-dopa in the treatment of Parkinson's disease. Adv Neurol 1973;2:161-72.
12 Reid JL, Calne DB, Vakil SD, et al. Plasma concentration of levodopa in parkinsonism before and after inhibition of peripheral decarboxylase. J Neurol Sci 1972;17:45-51

13 Pinder RM, Brogden RN, Sawyer PR, et al. Levodopa and decarboxylase inhibitors: a review of their clinical pharmacology and use in the treatment of parkinsonism. Drugs 1976;11:329-77.

14 Giovannoni G, van Schalkwyk J, Fritz V U, et al. Bradykinesia akinesia incoordination test (BRAIN TEST): an objective computerised assessment of upper limb motor function. J Neurol Neurosurg Psychiatry 1999;67:624-9.

15 Durif $\mathbf{F}$, Vidailhet $M$, Debilly $B$, et al. Worsening of levodopa-induced dyskinesias by motor and mental tasks. Mov Disord 1999;14:242-5.

16 Goetz CG, Stebbins GT, Shale HM, et al. Utility of an objective dyskinesia rating scale for Parkinson's disease: inter- and intrarater reliability assessment. Mov Disord 1994:9:390-4.

17 May PR, Lee MA, Bacon RC. Quantitative assessment of neuroleptic-induced extrapyramidal symptoms: clinical and nonclinical approaches. Clin Neuropharmacol 1983;6:S35-51.

18 Manson AJ, Schrag A, Lees AJ. Low dose olanzapine for levodopa-induced dyskinesias in Parkinson's disease. Neurology 2000;55:795-9.

19 Steiger MJ, Stocchi F, Bramante L, et al. The clinical efficacy of single morning doses of levodopa methyl ester: dispersible madopar and sinemet plus in Parkinson disease. Clin Neuropharmacol 1992;15:501-4

20 Merello M, Pikielny R, Cammarota A, et al. Comparison of subcutaneous apomorphine versus dispersible madopar latency and effect duration in Parkinson's disease patients: a double-blind single-dose study. Clin Neuropharmacol 1997;20:165-7.

21 Bermejo Pareja F, Martinez-Martin P, Muradas V, et al. Carbidopa dosage modifies L-dopa induced side effects and blood levels of L-dopa and other amino acids in advanced parkinsonism. Acta Neurol Scand 1985:72:506-11.

22 Kaakkola S, Teräväinen $\mathrm{H}$, Ahtila S, et al. Effect of entacapone, a COMT inhibitor, on clinical disability and levodopa metabolism in parkinsonian patients. Neurology 1994;44:77-80.

23 Bergmark J, Carlsson A, Granerus AK, et al. Decarboxylation of orally administered L-dopa in the human digestive tract. Naunyn-Schmiedebergs Arch Pharmacol 1972;272:437.

24 Bakke OM, Scheline RR. Inhibition of a minor pathway of L-dopa metabolism in the intestinal lumen using a decarboxylase inhibitor (Ro 4-4602). J Pharm Pharmacol 1974;26:377.

25 Pletscher A, Bartholini G. Selective rise in brain dopamine by inhibition of extracerebral levodopa decarboxylation. Clin Pharmacol Ther 1971;12:117-31.

26 Bianchine JR, Messiha FS, Hsu TH. Peripheral aromatic amino acid decarboxylase inhibitor in parkinsonism. II. Effect on metabolism of L-2- ${ }^{14} \mathrm{C}$ dopa. Clin Pharmacol Ther 1972;13:584-94.

27 Nutt JG, Woodward WR, Anderson JL. The effect of carbidopa on the pharmacokinetics of intravenously administered levodopa: the mechanism of action in the treatment of parkinsonism. Ann Neurol 1985;18:537-43.

28 Cedarbaum JM, Kutt H, Dhar AK, et al. Effect of supplemental carbidopa on bioavailability of L-dopa. Clin Neuropharmacol 1986;9:153-9.

29 Dunner DL, Brodie KH, Goodwin FK. Plasma dopa response to levodopa administration in man: effects of a peripheral decarboxylase inhibitor. Clin Pharmacol Ther $1971 ; 12: 212$

30 Pappert EJ, Buhrfiend C, Lipton JW, et al. Levodopa stability in solution: time course, environmental effects, and practical recommendations for clinical use. Mov Disord 1997:11:24-6.

31 Kurth MC, Tetrud JW, Irwin I, et al. Oral levodopa/carbidopa solution versus tablets in Parkinson's patients with severe fluctuations: a pilot study. Neurology 1993;43:1036-9

32 Yazawa I, Terao Y, Sai I, et al. Gastric acid secretion and absorption of levodopa in patients with Parkinson's disease - the effect of supplement therapy to gastric acid. Rinsho Shinkeigaku 1994;34:264-6.

33 Fahn S. "On-off" phenomenon with levodopa therapy in parkinsonism. Neurology 1974;24:431-41

34 Mahajani SS, Doshi V, Manyam BV. Bioavailability of L-dopa from HP-200 in five human volunteers. Phytother Res 1996:10:254-6.

35 Nutt JG. Pharmacodynamics of levodopa in Parkinson's disease. Clin Exp Pharmacol Physiol 1995;22:837-40.

36 Birkmayer W. Experimentelle Ergebnisse über die Kombinationsbehandlung des Parkinson-Syndroms mit L-Dopa und einem Decarboxylasehemmer (Ro 4-4602). Wien Klin Wochenschr 1969;81:677-9.

37 Shindler JS, Finnerty GT, Towlson K, et al. Domperidone and levodopa in Parkinson's disease. Br J Clin Pharmacol 1984; 18:959-62.

38 Kempster PA, Bogetic Z, Secombe JW, et al. Motor effects of broad beans (Vicia fava) in Parkinson's disease: single dose studies. Asia Pac J Clin Nutr 1993;2:85-9.

39 Melvin E, Daxenbichler $\mathrm{CH}$, Etten $\mathrm{V}$, et al. L-dopa recovery from mucuna seed. J Agric Food Chem 1972;20:1046-8.

40 Miller ER. Dihydroxyphenylalanine, a constituent of the velvet bean. J Biol Chem 1920;44:481-6.

41 Guggenheim M. Dioxyphenylalanin, eine neue Aminosaeure aus Vicia fava. Z Physiol Chem 1912;88:276-84.

42 Rabey JM, Vered Y, Shabtai H, et al. Improvement of parkinsonian features correlate with high plasma levodopa values after broad bean (Vicia fava) consumption. J Neurol Neurosurg Psychiatry 1992;55:725-7.

43 Apaydin H, Ertan S, Özekmekci S. Broad bean (vicia fava) - a natural source of L-dopa - prolongs "on" periods in patients with Parkinson's disease who have "on-off" fluctuations. Mov Disord 2000;15:164-6.

44 Tripathi YB, Upadhyay AK. Effect of the alcohol extract of the seeds of Mucuna pruriens on free radicals and oxidative stress in albino rats. Phytother Res 2002;16:534-8. 